\title{
Development of polyether urethane intravaginal rings for the sustained delivery of hydroxychloroquine
}

This article was published in the following Dove Press journal:

Drug Design, Development and Therapy

9 October 2014

Number of times this article has been viewed

\author{
Yufei Chen' \\ Yannick Leandre Traore' \\ Amanda $\mathrm{Li}^{\prime}$ \\ Keith R Fowke ${ }^{2,3}$ \\ Emmanuel A Ho' \\ 'Laboratory for Drug Delivery \\ and Biomaterials, Faculty of Pharmacy, \\ ${ }^{2}$ Department of Medical Microbiology \\ and Infectious Diseases, ${ }^{3}$ Department \\ of Community Health Sciences, \\ Faculty of Medicine, University of \\ Manitoba, Winnipeg, MB, Canada
}

\begin{abstract}
Hydroxychloroquine (HCQ) has been shown to demonstrate anti-inflammatory properties and direct anti-HIV activity. In this study, we describe for the first time the fabrication and in vitro evaluation of two types of intravaginal ring (IVR) devices (a surfaced-modified matrix IVR and a reservoir segmental IVR) for achieving sustained delivery ( $>14$ days) of HCQ as a strategy for preventing male-to-female transmission of HIV. Both IVRs were fabricated by hot-melt injection molding. Surface-modified matrix IVRs with polyvinylpyrrolidone or poly(vinyl alcohol) coatings exhibited significantly reduced burst release on the first day (6.45\% and $15.72 \%$ reduction, respectively). Reservoir IVR segments designed to release lower amounts of HCQ displayed near-zero-order release kinetics with an average release rate of $28.38 \mu \mathrm{g} / \mathrm{mL}$ per day for IVRs loaded with aqueous HCQ and $32.23 \mu \mathrm{g} / \mathrm{mL}$ per day for IVRs loaded with HCQ mixed with a rate-controlling excipient. Stability studies demonstrated that HCQ was stable in coated or noncoated IVRs for 30 days. The IVR segments had no significant effect on cell viability, pro-inflammatory cytokine production, or colony formation of vaginal and ectocervical epithelial cells. Both IVR systems may be suitable for the prevention of HIV transmission and other sexually transmitted infections.
\end{abstract}

Keywords: intravaginal delivery, matrix system, reservoir system, polymeric drug carrier, drug release, microbicide, HIV/AIDS

\section{Introduction}

In 2010, it was estimated that 2.7 million people became newly infected with HIV, with Sub-Saharan Africa being the region most affected by AIDS. ${ }^{1}$ More than half of all people living with HIV are women, ${ }^{2}$ and sexual intercourse is the main route of transmission. ${ }^{3}$ In some regions (eg, Sub-Saharan Africa), young woman aged 15-24 years are as much as eight times more likely than men to be HIV-positive. ${ }^{1}$ Thus, there is a desperate need to develop innovative strategies that provide femalecontrolled prevention of HIV infection.

Microbicides containing active agents that can be topically applied to the vagina are currently being investigated for use as HIV prophylactic strategies. The Centre for the AIDS Program of Research in South Africa (CAPRISA) 004 trial demonstrated that a vaginal microbicide containing an antiretroviral drug (tenofovir) could reduce the acquisition of HIV by 39\%. ${ }^{4}$ More recently, the Vaginal and Oral Interventions to Control the Epidemic (VOICE) trial ${ }^{5}$ also evaluated the safety and effectiveness of the same tenofovir gel formulation, but unfortunately, it failed to show significant reduction in HIV acquisition over placebo gel when used daily. ${ }^{5}$ The low user adherence of tenofovir gel and the inconvenient dosing regimen (the gel should be
Correspondence: Emmanuel A Ho Laboratory for Drug Delivery and Biomaterials, Faculty of Pharmacy, University of Manitoba, Apotex Centre, 750 McDermot Ave, Room 329, Winnipeg, MB R3E 0T5, Canada

Tel +l 2042723180

Fax +I 2044747617

Email emmanuel_ho@umanitoba.ca 
applied before and after sexual intercourse) may be issues that contributed to its poor effectiveness in preventing HIV transmission. ${ }^{6}$ Thus, development of vaginal microbicides capable of providing sustained drug release can potentially increase user adherence and improve therapeutic efficacy. One possible approach is to formulate therapeutic drugs into intravaginal rings (IVRs). IVR drug delivery systems have been marketed since 1992 for hormone replacement therapy, but the use of IVRs as microbicides is relatively new. Compared with other vaginal microbicides such as gels ${ }^{7}$ or tablets, ${ }^{8}$ drug delivery via an IVR has several advantages, such as the ability to provide sustained, controlled drug release over extended periods ( $>14$ days) and the absence of leakage and messiness (such as is associated with gels). Recently, a study evaluating drug-free IVRs in HIV-negative African female participants demonstrated that more than $95 \%$ of participants who used the placebo IVR every day for at least 12 hours during the entire 12 weeks study had no major adverse effects. ${ }^{9}$ This suggests that IVRs are relatively safe and have high user acceptability. Several IVR medical devices have been developed preclinically for the purpose of sustained release of either single antiretroviral drugs or multiple drugs. ${ }^{10-13}$

Successful development of IVRs for the delivery of drugs requires the selection of an appropriate polymer. In the case of hydrophilic drugs, the ideal polymer for IVR fabrication should satisfy several conditions. First, it should provide high drug solubilization capacity so that a sufficient quantity of the drug could be incorporated into the IVR formulation. Second, the polymer should be able to control the drug release based on properties such as water swellability and drug diffusion within the polymeric matrix. Last, its mechanical and chemical properties should allow the IVR to remain within the vaginal lumen without eliciting tissue damage, and the selected polymer should be stable in the acidic vaginal environment $(\mathrm{pH}, 3.5-4.2)$, which is a result of lactic acid present in the vagina. ${ }^{14}$

In the current study, we have developed an IVR for the intravaginal delivery of hydroxychloroquine (HCQ). HCQ, a lysosomotropic amine and a hydroxyl derivative of chloroquine, has been used for the treatment of acute malaria ${ }^{15}$ and autoimmune diseases such as lupus ${ }^{16}$ and rheumatoid arthritis. ${ }^{17} \mathrm{HCQ}$ has been shown to exhibit antibacterial activity both in vitro ${ }^{18}$ and in vivo ${ }^{19,20}$ and has demonstrated direct anti-HIV activity by increasing endosomal $\mathrm{pH}$, alteration of enzymes required for gp 120 production, ${ }^{21,22}$ and impairment of gp 120, integrase, and Tat production. ${ }^{23,24}$ Studies have also demonstrated that HCQ can significantly reduce viral loads in
HIV-1-infected patients with a CD4 count between 200 and 500 cells $/ \mathrm{mm}^{3}{ }^{35,26}$ Furthermore, HCQ has been reported to demonstrate anti-inflammatory ${ }^{27,28}$ and immune modulatory effects. ${ }^{23,28,29}$ Since studies have shown that inflammation of the female genital tract (FGT) can increase susceptibility to HIV-1 infection, ${ }^{30}$ the anti-inflammatory effects of HCQ may potentially be protective. Our IVR is intended to release HCQ locally within the FGT, thus minimizing systemic absorption and reducing systemic toxicity.

We report, for the first time to our knowledge, the fabrication and in vitro characterization of two IVR medical devices (surface-modified matrix and reservoir segmented IVRs), which can provide sustained release and varying release rates (high and low) of HCQ for more than 14 days. We evaluated the effects of polyvinylpyrrolidone (PVP) and poly(vinyl alcohol) (PVA) coating on the drug release profile of matrix IVR systems. In addition, stability of HCQ within the matrix IVR formulation and effect of drug-free IVRs on the viability of vaginal and cervical epithelial cells in vitro were investigated in the current study.

\section{Materials and methods Materials}

Medical-grade nonbiodegradable polyether urethane Tecophilic ${ }^{\circledR}$ HP-93A-100 (referred to as PU-93A in this article) and HP-60D-35 (referred to as PU-60D) were purchased from Lubrizol (Wickliffe, OH, USA). HCQ was purchased from TCI America (Portland, OR, USA). Ammonium acetate (high-performance liquid chromatography [HPLC] grade), sodium phosphate dibasic (American Chemical Society grade), methylene chloride (HPLC grade), chloroform (HPLC grade), and dimethylacetamide (HPLC grade) were purchased from Fisher Scientific (Whitby, ON, Canada). Water, methanol, and acetonitrile (all HPLC grade) were purchased from VWR International LLC (Batavia, IL, USA). PVP (average molecular weight, $\sim 360,000$ ) and PVA (average molecular weight, 31,000 50,000) were purchased from Sigma-Aldrich (Whitby, ON, Canada). Methocel ${ }^{\mathrm{TM}} \mathrm{K} 100 \mathrm{M}$ premium hydroxypropyl methylcellulose (HPMC; assayed apparent viscosity, 97,579 $\mathrm{mPa} \cdot \mathrm{s}$ ) was kindly supplied by the Dow Chemical Company (New Milford, CT, USA). Dynapurge ${ }^{\circledR}$ M polymer was kindly supplied by Shuman Plastics (Buffalo, NY, USA).

\section{Fabrication of matrix and reservoir HCQ-loaded IVR segments}

To fabricate matrix HCQ IVR, the solvent casting method was used for the incorporation of HCQ into the PU-93A 
matrix. PU-93A was first dried in an oven at $80^{\circ} \mathrm{C}$ overnight to remove any absorbed moisture. Briefly, $20 \mathrm{~g}$ PU-93A was added to $300 \mathrm{~mL}$ methylene chloride in a $1 \mathrm{~L}$ roundbottom flask. The polymer was dissolved by stirring the mixture at room temperature for 6 hours. After complete dissolution of the polymer, a concentrated HCQ solution (200 mg/mL dissolved in methanol:water $=1: 1, \mathrm{v} / \mathrm{v}$ ) was added to the round-bottom flask containing the dissolved polymer to yield either a $2 \%$ or $4 \%(\mathrm{w} / \mathrm{w})$ drug-containing PU-93A solution. The drug-containing PU-93A solution was allowed to mix overnight. Once thoroughly mixed, the drug-containing PU-93A solution was poured into a Pyrex $^{\circledR}$ crystallizing dish (VWR, Batavia, IL, USA) and methylene chloride was evaporated in a fume hood to form HCQ-loaded films. The films were then placed on high vacuum and considered free of methylene chloride when the film mass remained constant over the course of 24 hours. Afterward, the dried films were cut into approximately $1 \mathrm{~cm}^{2}$ pieces and stored in a container with desiccant at $-20^{\circ} \mathrm{C}$ in the dark until further use. Fabrication of PU-60D matrix IVR was conducted under the same process.

IVRs were fabricated by hot-melt injection molding (Medium Machinery, LLC, Woodbridge, VA, USA) at a temperature of $140^{\circ} \mathrm{C}$ for PU-93A and $160^{\circ} \mathrm{C}$ for PU-60D. The pre-cut, HCQ-loaded film pieces were loaded into the feeder, and the melted HCQ-loaded PU was manually injected into a custom-fabricated, preheated aluminum mold with cavities for two varying sizes of IVRs (Cardatech, Alexandria, VA, USA). The larger IVR has dimensions of $55 \mathrm{~mm}$ outer diameter (OD) and $5.5 \mathrm{~mm}$ cross-sectional diameter (XD), whereas the smaller IVR has dimensions of $25 \mathrm{~mm}$ OD and $5 \mathrm{~mm}$ XD. These dimensions have been previously evaluated for use in humans and macaques, respectively. ${ }^{31}$ The OD and XD of each fabricated IVR were measured with a digital caliper, and the mass of each IVR was measured using an analytical balance. In the current study, only the small-size HCQ-loaded IVRs (25 mm OD with $5 \mathrm{~mm}$ XD) were used for the release and stability studies.

Randomly selected 4\% (w/w) HCQ-loaded IVR segments were coated with either PVP or PVA for release and stability studies. Briefly, 10\% PVP and 5\% PVA solutions were prepared in water $(5 \%$ PVA solution was prepared by heating the solution at $80^{\circ} \mathrm{C}$ overnight to completely dissolve PVA). Next, $100 \pm 5 \mathrm{mg}$ drug-containing segments were dip-coated in the PVP or PVA solutions for 2 seconds, followed by incubation in an oven at $50^{\circ} \mathrm{C}$ for 15 minutes to evaporate water. Each segment was coated twice following this process before it was used for release or stability studies.
To fabricate reservoir IVRs (res-IVR), the PU-93A and PU-60D pellets were dried overnight in an oven at $80^{\circ} \mathrm{C}$. Arc-shaped res-IVR segments (approximately $80^{\circ}$ arch) were then fabricated by hot-melt injection molding at temperatures of $140^{\circ} \mathrm{C}$ and $160^{\circ} \mathrm{C}$ for PU-93A and PU-60D, respectively. Briefly, PUs were loaded into the feeder of the hot-melt injection molder, and the melted PUs were injected into a custom-designed, preheated aluminum mold with cavities for small-size res-IVRs (Cardatech, Alexandria, VA, USA). The res-IVR segments had target dimensions of $25 \mathrm{~mm}$ OD and $5 \mathrm{~mm}$ XD and a wall thickness of $0.75 \mathrm{~mm}$, measured with a digital caliper. Loctite $^{\circledR} 4013^{\mathrm{TM}}$ Prism $^{\circledR}$ instant adhesive (Henkel Corporation, Mississauga, ON, Canada) was used to attach either one or three reservoir segments on to the proper length of precut PU-60D matrix segments to form full-size small res-IVRs. The res-IVR segment lumen was filled with HCQ solution or HCQ/K100M semisolid (at 1:1 w/w ratio). The HCQ/K100M semisolid was prepared using a two-syringe mixing method. Briefly, to make a semisolid with the desired weight ratio of HCQ to HPMC, the HPMC powder was first weighed into a $10 \mathrm{~mL}$ beaker. A solution of $\mathrm{HCQ}$ at $60 \mathrm{mg} / \mathrm{mL}$ was then added in a step-wise fashion and hand-mixed with HPMC powder thoroughly. Afterwards, all the content was transferred into a $5 \mathrm{~mL}$ syringe attached to another $5 \mathrm{~mL}$ syringe via a $1.5 \mathrm{~cm}$ length of polypropylene tubing with an internal diameter of $3 \mathrm{~mm}$. HCQ/HPMC semisolid was mixed thoroughly by passing the sample (minimum of 80 passes) from one syringe to another.

\section{Extraction of HCQ from matrix IVR segments and $\mathrm{HCQ} / \mathrm{K} / 00 \mathrm{M}$ semisolid}

Drug extraction from matrix IVRs was performed using a previously described method with slight modifications. ${ }^{32}$ Briefly, 50 \pm 2 mg HCQ-loaded PU-93A (or PU-60D) IVR segments were weighed and added to $5 \mathrm{~mL}$ volumetric flasks. Approximately $2 \mathrm{~mL}$ dimethylacetamide (or chloroform) was added into each volumetric flask and placed on a Gyrotory Waterbath Shaker (New Brunswick Scientific, Edison, NJ, USA) at $150 \mathrm{rpm}$ overnight to dissolve the polymer. After complete dissolution, dimethylacetamide was added to fill up to volume, and the sample was vortexed. Afterward, a $100 \mu \mathrm{L}$ sample was added into $900 \mu \mathrm{L}$ of $50 \mathrm{mM}$ ammonium acetate buffer and vortexed to precipitate the polymer. The samples were then centrifuged at $20,000 \times g$, and the supernatant was filtered using an Acrodisc ${ }^{\circledR} 0.45 \mu \mathrm{m}$ PTFE membrane (Pall Life Sciences, Mississauga, ON, Canada) in a HPLC vial insert for HCQ concentration analysis, which will be described later. 
Extraction efficiency was determined by dissolving $50 \pm 2 \mathrm{mg}$ drug-free PU-93A (or PU-60D) segments in $2 \mathrm{~mL}$ dimethylacetamide in $5 \mathrm{~mL}$ volumetric flasks and placed on the same shaker at $150 \mathrm{rpm}$ overnight. A known amount of drug was added to the mixture and placed back on the shaker for another 4 hours. The solution was then filled to volume with dimethylacetamide, followed by vortexing. Drug extraction was performed on the polymer solution containing a known amount of HCQ, using the same method described earlier. The calculated HCQ concentration from HPLC analysis in these "spiked" controls was then used to calculate the extraction efficiency.

HCQ loading in the semisolid was determined by the extraction of HCQ from the HCQ/K100M semisolid. Briefly, $10 \pm 0.5 \mathrm{mg}$ semisolid was weighed directly into a $1.5 \mathrm{~mL}$ microcentrifuge tube and dissolved in $1 \mathrm{~mL}$ sterile double distilled water. Extraction was performed by vortexing the tube at 2,000 rpm overnight at $4^{\circ} \mathrm{C}$. Extraction samples were diluted 100 times before subjection to the HPLC analysis described later. HCQ extraction efficiency was determined by spiking a similar amount of HCQ into $10 \pm 0.5 \mathrm{mg}$ of the HCQ-free K100M semisolid via the same process and was similarly calculated, as mentioned earlier.

\section{Reversed-phase HPLC quantitation of $\mathrm{HCQ}$}

Analysis of HCQ was performed using a reversed-phase HPLC method that was described previously, with slight modifications. ${ }^{33}$ For analysis of release study samples, a Waters Nova-Pak ${ }^{\circledR}$ C18 column $(4 \mu \mathrm{m}, 3.9 \times 150 \mathrm{~mm})$ was used under an isocratic condition on a Shimadzu LC-2010A HPLC system. The mobile phase consisted of methanol, acetonitrile, and $58 \mathrm{mM}$ sodium phosphate dibasic buffer $(4: 22: 74, \mathrm{v} / \mathrm{v})$ containing $6 \mathrm{mM}$ heptanesulfonic acid and adjusted to $\mathrm{pH} 3.1$ with concentrated phosphoric acid. Flow rate was maintained at $1.0 \mathrm{~mL} /$ minute, and ultraviolet detection was set at $343 \mathrm{~nm}$. Column temperature was maintained at $25^{\circ} \mathrm{C}$. The retention time of HCQ was approximately 5.9 minutes. A linear calibration curve of HCQ was obtained in the range of $48-1,000 \mathrm{ng} / \mathrm{mL}\left(r^{2}>0.999\right)$, using a $40 \mu \mathrm{L}$ injection. The lower limit of quantification for HCQ was $20 \mathrm{ng} / \mathrm{mL}$, with a signal to noise ratio greater than 10 .

\section{In vitro release studies}

From both drug-free and HCQ-loaded IVR segments, $100 \pm 5 \mathrm{mg}$ matrix was prepared for in vitro release studies by adhering two small pieces of acrylic sheets $\left(1 \times 1 \mathrm{~cm}^{2}\right)$ at each end of the segments, using Loctite $^{\circledR} 4013^{\text {TM }}$ Prism $^{\circledR}$ instant adhesive
(Henkel Corporation) to prevent HCQ release. This is to mimic drug release from a "complete" IVR that does not have exposed ends. The "capped" segments were then incubated for 18 days in $25 \mathrm{mM}$ sodium acetate buffer $(\mathrm{pH}, 4)$ in an incubating orbital shaker set to $37^{\circ} \mathrm{C}$ and $100 \mathrm{rpm}$. Sink conditions were maintained by replacing the entire release medium daily. Release samples $(1 \mathrm{~mL})$ were collected at determined intervals throughout the study (approximately $24 \pm 0.5$ hours) and analyzed by HPLC for HCQ concentrations. The $\mathrm{pH}$ of the daily release medium was monitored for the entire study period. The release data were scaled up to represent the HCQ release from a full-size small matrix IVR $(25 \mathrm{~mm} \mathrm{OD} \times 5 \mathrm{~mm} \mathrm{XD})$. The weight and the dimensions (length and diameter) of each segment were recorded both at the beginning and the end of the study.

The res-IVR segment lumens were either loaded with aqueous HCQ solution or HCQ/K100M semisolid containing $4 \pm 0.5 \mathrm{mg}$ HCQ. The ends of each segment were capped with custom-made silicone lids and sealed with Loctite $^{\circledR}$ 4013 ${ }^{\mathrm{TM}}$ Prism $^{\circledR}$ instant adhesive (Henkel Corporation). Release study was performed under the same conditions described earlier.

\section{Accelerated stability test}

IVRs ( $25 \mathrm{~mm}$ OD and $5 \mathrm{~mm} \mathrm{XD}$ ) were cut into $50 \pm 10 \mathrm{mg} \mathrm{seg-}$ ments and randomly selected, weighed, and wrapped in aluminum foil. The wrapped segments were then placed either at room temperature (RT) or at $40^{\circ} \mathrm{C} / 75 \%$ relative humidity (RH) in an APT.line ${ }^{\mathrm{TM}}$ KBF-P 240 climatic chamber (Binder, Bohemia, NY, USA). At various intervals $(0,15$, and 30 days), the samples were collected and stored in $-80^{\circ} \mathrm{C}$ until the time for drug extraction and HPLC analysis.

\section{Matrix IVR segment swelling test}

Noncoated and coated HCQ-containing matrix IVR segments, $100 \pm 10 \mathrm{mg}$, were incubated for 7 days in $25 \mathrm{mM}$ sodium acetate buffer $(\mathrm{pH}, 4)$ in an incubating orbital shaker set to $37^{\circ} \mathrm{C}$ and $100 \mathrm{rpm}$ (Thermo Scientific, Asheville, NC, USA). Weights and cross-sectional diameters of IVRs were measured using an analytical balance and digital caliper, respectively.

\section{In vitro cytotoxicity evaluation of IVR segments}

\section{Cell culture conditions}

In vitro cytotoxicity studies were evaluated, using the human vaginal epithelial cell line VK2/E6E7 and ectocervical epithelial cell line Ect1/E6E7, obtained from the American Type 
Culture Collection (ATCC, Rockville, MD, USA). The cells were cultured in keratinocyte-serum free medium (K-SFM) containing $0.1 \mathrm{ng} / \mathrm{mL}$ recombinant human epidermal growth factor, $50 \mathrm{mg} / \mathrm{mL}$ bovine pituitary extract (Life Technologies, Carlsbad, CA, USA), $0.4 \mathrm{mM} \mathrm{CaCl}_{2}$, and $1 \%$ penicillin/ streptomycin (Sigma-Aldrich). Cells were maintained in an incubator at $37^{\circ} \mathrm{C}$ and $5 \% \mathrm{CO}_{2}$ before the treatment.

\section{IVR segment elution medium preparation}

The effect of drug-free IVR segments on cell viability was evaluated using an elution assay. Briefly, IVR segments (either noncoated or coated with PVP/PVA) were sterilized by immersion in $70 \%$ isopropanol for 10 seconds and airdried in a sterile biosafety cabinet. The IVR segments were then put into a sterile $50 \mathrm{~mL}$ tube containing $10 \mathrm{~mL} \mathrm{K-SFM}$, using aseptic technique. The samples were incubated at $37^{\circ} \mathrm{C}$ for $1,7,15$, and 30 days in an incubating orbital shaker at a speed of $100 \mathrm{rpm}$. At the desired intervals, the elution medium was collected using aseptic technique by transferring the elution medium into a sterile $15 \mathrm{~mL}$ tube and storing it at $-80^{\circ} \mathrm{C}$ until further analysis.

\section{Cell treatment}

Next, $1 \mathrm{M}$ acrylamide was prepared in K-SFM and filtered using a $0.2 \mu \mathrm{m}$ membrane. Acrylamide K-SFM solution was used to induce cell death as a positive control for the CellTiter $96^{\circledR}$ AQueous One Solution Cell Proliferation Assay (MTS assay, Promega Corporation, Madison, WI, USA). Lipopolysaccharide (from Escherichia coli 0111:B4; Sigma) was suspended in $1 \mathrm{~mL}$ sterile phosphate-buffered saline (PBS) solution to yield a $1 \mathrm{mg} / \mathrm{mL}$ stock solution. Diluted lipopolysaccharide $(50 \mu \mathrm{g} / \mathrm{mL})$ prepared in K-SFM was used as positive control for interleukin 6 (IL-6) and IL-8 enzyme-linked immunosorbent assay (ELISA; R\&D System Inc., Minneapolis, MN, USA). Nonoxynol-9 (200 $\mu \mathrm{g} / \mathrm{mL}$; Spectrum Chemical Corp., New Brunswick, NJ, USA) in K-SFM was used as a positive control for IL-1 $\beta$ ELISA (R\&D System). Drug-free K-SFM was used as negative control. VK2/E6E7 or Ect1/E6E7 cells were seeded at $2.5 \times 10^{4}$ per 100 $\mu \mathrm{L}$ per well, and after overnight adhesion, the medium was replaced with $100 \mu \mathrm{L}$ positive and negative control medium and elution medium collected at different intervals.

\section{MTS assay and cytokine ELISA}

After 24 hours of elution medium treatment, $20 \mu \mathrm{L}$ MTS assay reagent was added into each well, followed by incubation at $37^{\circ} \mathrm{C}$ in the dark for 1 hour, as suggested by the manufacturer. Absorbance of each well at $490 \mathrm{~nm}$ was recorded using a Synergy HT Multi-Mode Microplate Reader (Biotek, Winooski, VT, USA). After 24 hours of incubation $\left(37^{\circ} \mathrm{C}, 5 \% \mathrm{CO}_{2}\right)$, supernatants in each well were collected for cytokine ELISA analysis. Levels of IL-1 $\beta$, IL-6, and IL-8 in VK2/E6E7 or Ect1/E6E7 supernatants were evaluated using ELISA kits obtained from R\&D Systems and data were analyzed using SigmaPlot 12.2 (Systat Software Inc., San Jose, CA, USA).

\section{Colony formation assay}

Colony formation assay was performed similar to other reported studies. ${ }^{33-35}$ Plating efficiencies for VK2/E6E7 and Ect1/E6E7 cells ranged between 9.5\%-20.2\% and $11.3 \%-21.9 \%$, respectively. Cells were seeded at a density of 800 cells/well in 12-well plates, and plating efficiencies for both cell lines were independent of the number of cells seeded (data not shown). After 2 hours of cell attachment, medium was replaced with $4 \mathrm{~mL}$ of either regular medium (negative control) or elution medium collected at different intervals. The cells were cultured without changing medium for 12 days until 50-200 colonies formed per well ${ }^{36}$ at $37^{\circ} \mathrm{C}$ and $5 \% \mathrm{CO}_{2}$. Thereafter, the medium was discarded and the colonies were gently washed once with warm PBS solution. The cells were fixed and stained using a mixture of $6.0 \%$ formaldehyde and $0.5 \%$ crystal violet (Alfa Aesar, Ward Hill, MA, USA; $2 \mathrm{~mL}$ per well for 30 minutes). After gentle rinsing, formed colonies containing more than 50 cells $^{37}$ were manually counted under a microscope. The colony-forming efficiency was calculated by dividing the average number of colonies with the number of cells inoculated further normalized to the negative control and expressed as a percentage of the negative control.

\section{Statistical analysis}

Data are presented as mean \pm standard deviation (SD). The $\mathrm{n}$-value refers to number of replicates performed for each study. Student's $t$-tests (unpaired, two-sample, unequal variance with two-tailed distribution) was performed on all results, with $P<0.05$ considered to be significant.

\section{Results}

\section{Fabrication of HCQ IVRs}

Schematic representation of matrix IVRs and res-IVRs along with the corresponding fabricated IVRs are shown in Figure 1. HCQ-loaded small-size matrix IVRs had actual measured diameters close to the target dimensions of $25 \mathrm{~mm}$ OD and $5 \mathrm{~mm} \mathrm{XD}$ (Table 1). On coating the IVRs with PVP or PVA, the dimensions of the IVRs slightly increased. 
A

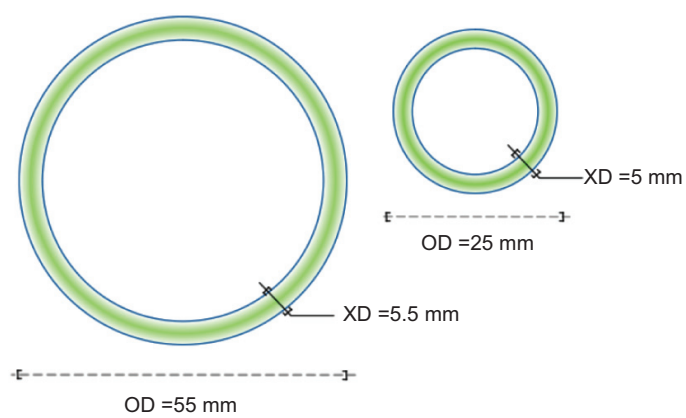

$\mathrm{OD}=55 \mathrm{~mm}$
B

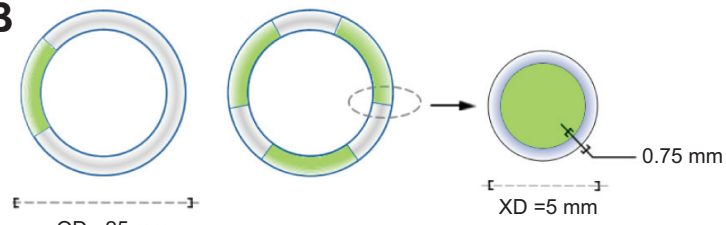

$\mathrm{OD}=25 \mathrm{~mm}$
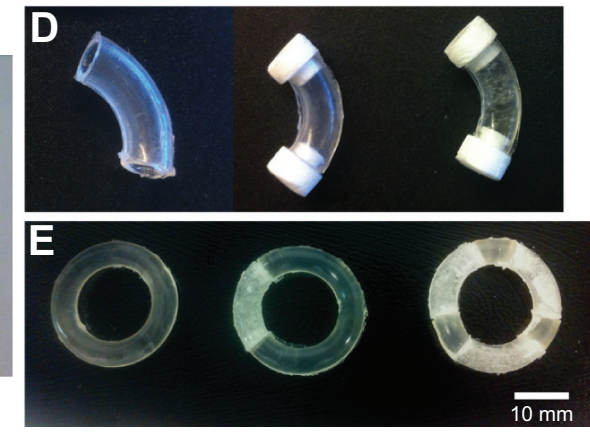

Figure I Drug-free and hydroxychloroquine (HCQ)-loaded matrix and reservoir intravaginal rings (IVRs).

Notes: Schematic designs of (A) large- and small-matrix IVRs with HCQ (green) dispersed within the PU matrix and (B) small res-IVRs containing different quantities of reservoir segments with preformulated HCQ filled in (green). Photographs of hot-melt injection-molded (C) PU-93A matrix IVRs: a large, drug-free matrix IVR (left, 55×5.5 mm), a small drug-free IVR (middle, $25 \times 5 \mathrm{~mm}$ ), and a HCQ-loaded small IVR (right, $25 \times 5 \mathrm{~mm}$ ). (D) PU-60D res-IVR segments fabricated via hot-melt injection for in vitro release studies: a res-IVR segment (left), an end-capped res-IVR segment (middle), and an end-capped res-IVR containing HCQ-free KI00M semisolid (right). (E) Full small-size PU-60D matrix IVR and res-IVRs: a small drug-free IVR (left, $25 \times 5 \mathrm{~mm}$ ), a small res-IVR containing one reservoir segment loaded with HCQ/KI00M (I:I wt ratio; middle) semisolid, and a small res-IVR containing three reservoir segments (right).

Abbreviation: res-IVRs, reservoir intravaginal rings; XD, cross-sectional diameter; OD, outer diameter; mm, millimeter; PU, polyether urethane.

The weight of the small-size placebo IVRs, HCQ-loaded IVRs, and coated HCQ-loaded IVRs ranged from 1.36 to $1.42 \mathrm{~g}$ (Table 1). Res-IVR segments fabricated from PU-93A and PU-60D had similar XD ( $(5.0 \mathrm{~mm})$ and wall thickness $(\sim 0.75$ mm) (Table 2).

HCQ extraction efficiency from the matrix IVR segments was $98.75 \% \pm 2.63 \%$ (mean $\pm \mathrm{SD} ; \mathrm{n}=6)$ and $96.37 \% \pm 2.17 \%$ for PU-93A and PU-60D matrix IVR segments, respectively. The actual measured loading of HCQ in the noncoated IVR segments for $2 \%$ and $4 \%$ (w/w) HCQ loadings were $1.99 \% \pm 0.08 \%$ and $3.93 \% \pm 0.12 \%$ (mean $\pm \mathrm{SD} ; \mathrm{n}=6$ ), respectively. Extraction of HCQ from PVP-coated and PVA-coated 4\% (w/w) segments demonstrated a drug loading of $3.80 \% \pm 0.1 \%$ (mean \pm $\mathrm{SD} ; \mathrm{n}=3$ ) and $3.81 \% \pm 0.2 \%$ (mean $\pm \mathrm{SD} ; \mathrm{n}=3$ ), respectively.
HCQ extraction efficiency from the HCQ/K100M semisolid was $96.47 \% \pm 1.89 \%$ (mean $\pm \mathrm{SD} ; \mathrm{n}=6)$.

\section{In vitro HCQ release}

Release studies demonstrated a sustained HCQ release from noncoated or PVA/PVP-coated matrix IVRs for 18 days (Figure 2A-C). During the entire study period, HCQ release followed a typical matrix drug diffusion release pattern ${ }^{34}$ in all matrix systems developed in the current study, which is characterized by a first-day burst release followed by a rapid drug elution phase and then a continuous decelerated release phase. In the current study, all matrix IVR systems exhibited burst release of HCQ on day 1, followed by rapid HCQ elution on day 2 to day 4, after which the efflux of HCQ entered

Table I Dimensions and weight of fabricated small-size matrix intravaginal rings

\begin{tabular}{llll}
\hline $\begin{array}{l}\text { Hydroxychloroquine-loaded } \\
\text { intravaginal ring }\end{array}$ & Outer diameter, $\mathbf{m m}$ & $\begin{array}{l}\text { Cross-sectional } \\
\text { diameter, mm }\end{array}$ & Weight, $\mathbf{g}$ \\
\hline Placebo & $25 \pm 0.2$ & $5.0 \pm 0.1$ & $1.36 \pm 0.04$ \\
$2 \%(w / w)$ & $25 \pm 0.4$ & $5.0 \pm 0.2$ & $1.38 \pm 0.01$ \\
$4 \%(w / w)$ & $25 \pm 0.3$ & $5.0 \pm 0.1$ & $1.39 \pm 0.04$ \\
$4 \%$ polyvinylpyrrolidone-coated & $25 \pm 0.7$ & $5.0 \pm 0.4$ & $1.40 \pm 0.04$ \\
$4 \%$ poly(vinyl alcohol)-coated & $25 \pm 0.5$ & $5.0 \pm 0.3$ & $1.42 \pm 0.01$ \\
\hline
\end{tabular}

Note: Data expressed as mean $\pm S D, n=3$. 
Table 2 Dimensions of fabricated PU-93A and PU-60D resintravaginal ring segments

\begin{tabular}{lll}
\hline PU used & $\begin{array}{l}\text { Cross-sectional } \\
\text { diameter, } \mathbf{~ m m}\end{array}$ & $\begin{array}{l}\text { Wall thickness, } \\
\mathbf{m m}\end{array}$ \\
\hline PU-93A & $5.0 \pm 0.1$ & $0.75 \pm 0.03$ \\
PU-60D & $5.0 \pm 0.2$ & $0.75 \pm 0.02$ \\
\hline
\end{tabular}

Note: Data expressed as mean $\pm S D, n=3$.

a decelerated release phase (Figure $2 \mathrm{~A}$ and $\mathrm{B}$ ). Within the first 24 hours, burst releases of $11.52 \mathrm{mg}(43.52 \% \pm 2.41 \%)$ and $21.77 \mathrm{mg}(41.08 \% \pm 2.24 \%)$ of initial loading (Figure 2A and B) were observed for noncoated $2 \%$ and $4 \%(w / w)$ HCQ IVRs, respectively. During the rapid drug elution phase (days $2-4$ ), noncoated $2 \%$ and $4 \%$ (w/w) IVRs exhibited average daily release of $2.65 \mathrm{mg}(10.23 \%)$ and $6.05 \mathrm{mg}$ (11.42\%), respectively. Daily HCQ release rates for the various matrix IVRs then gradually decreased to approximately $0.59 \%-0.92 \%$ per day on day 10 , and further to approximately $0.15 \%-0.59 \%$ per day on day 14 (Figure $2 \mathrm{~A}$ and B). During the 18 day study period, a total of $83.83 \% \pm 3.57 \%$ and $85.51 \% \pm 1.81 \%$ HCQ were released from $2 \%$ and $4 \%$ (w/w) HCQ-loaded IVRs, respectively (Figure 2C). PVPand PVA-coated IVR segments demonstrated a reduced burst release on the first day: $34.36 \% \pm 2.39 \%$ (6.45\% reduction) and $25.36 \% \pm 2.62 \%$ (15.72\% reduction) of initial loaded HCQ in PVP- and PVA-coated segments, respectively (Figure 2B).

In an attempt to reduce the burst release even further and to achieve controlled HCQ release, we altered the IVR design and fabricated res-IVRs using the same high-water-swellable PU-93A and low-water-swellable PU-60D. The first 7 day release profile from different IVR segments with the same $4 \mathrm{mg}$ HCQ loading was compared in Figure 2D and E. Although the first-day burst release was further decreased to $37.91 \% \pm 3.51 \%$ of the total loading, using PU-93A res-IVR segments, $79.69 \%$ of the total loading was released within the first 7 days of the study period (Figure 2D). Similarly, matrix IVR segments fabricated from the lower swellable polymer PU-60D showed a reduced daily HCQ release profile with a decreased first-day burst release $(17.94 \% \pm 7.99 \%$; Figure 2E). In contrast, using PU-60D res-IVR segments loaded with aqueous HCQ, the first-day burst release was significantly decreased to $9.77 \% \pm 0.73 \%$, with an average daily release of $8.65 \%$ per day within 7 days (Figure 2E). Furthermore, we evaluated the rate of release from the same res-IVR that was loaded with HCQ mixed with HPMC as a rate-controlling excipient. This $\mathrm{HCQ} / \mathrm{K} 100 \mathrm{M}$ semisolid mixture eliminated the burst release entirely with a controlled release rate of
$5.66 \%$ per day within the initial 7-day period (Figure 2E) Res-IVR segments containing HCQ/K100M semisolid were capable of providing near-zero-order release of HCQ (linear cumulative HCQ release over time, with $R^{2}=0.981$ ) at a rate of $32.23 \mu \mathrm{g} / \mathrm{mL}$ per day (3.85\%) for 24 days (Figure $2 \mathrm{~F}$ and $\mathrm{G}$ ). During the entire 24 day study period, preformulation of HCQ into a HCQ/K100M enabled a more steady release rate in comparison with the aqueous HCQ at the same loading (Figure 5F), and a total of $85.14 \% \pm 5.17 \%$ and $92.10 \% \pm 6.16 \%$ HCQ was released from PU-60D res-IVR segments containing $4 \mathrm{mg}$ HCQ in the forms of aqueous solution and HCQ/ K100M semisolid, respectively (Figure 2G).

During the entire release study, there were no significant changes in $\mathrm{pH}$ observed in the daily collected release medium (data not shown), indicating that the released HCQ did not alter the $\mathrm{pH}$ of the release buffer.

\section{Stability of HCQ-loaded matrix IVR segments}

Accelerated stability testing of coated and noncoated HCQloaded IVR segments ( $2 \%$ and $4 \% \mathrm{w} / \mathrm{w})$ were conducted at room temperature and at $40^{\circ} \mathrm{C} / 75 \%$ relative humidity. In comparison to the controls ( $t=$ day 0 ), no significant difference in HCQ stability (no drug loss or degradation) was observed between the noncoated and PVP- or PVA-coated matrix IVR segments during the 30 days study period at room temperature or at $40^{\circ} \mathrm{C} / 75 \%$ relative humidity, as determined by HPLC (Figure 3).

\section{Matrix IVR segment swelling test}

To investigate the effect of polymer swelling on drug release, HCQ-loaded matrix IVR segments (either noncoated or coated with PVP/PVA) were incubated in sodium acetate buffer $(\mathrm{pH}, 4)$ at $37^{\circ} \mathrm{C}$ for 7 days. The segments began to absorb water within 24 hours in buffer, with the noncoated segments reaching an equilibrated swelled state (no significant weight increase) within 2 days (Figure 4). In contrast, PVP- and PVA-coated segments reached their equilibrated swelled states after 5 days $(P<0.05)$. Compared with their initial dry weights, the equilibrated swelled weights of the noncoated, PVP-coated, and PVA-coated segments were $91.86 \%, 97.63 \%$, and $97.56 \%$ of their initial mass, respectively. After 7 days, the cross-sectional diameters of the noncoated, PVP-coated, and PVA-coated segments were $6.0 \pm 0.2,6.0 \pm 0.2$, and $6.0 \pm 0.4 \mathrm{~mm}$, respectively. As shown in Figure 4, after reaching the equilibrated swelled states, the increased mass in both the noncoated and coated PU-93A segments were nearly $100 \%$ of their initial weight. However, 
A

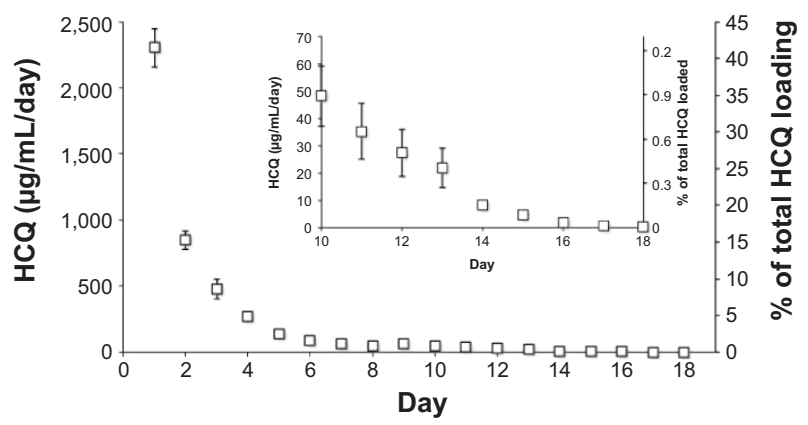

C

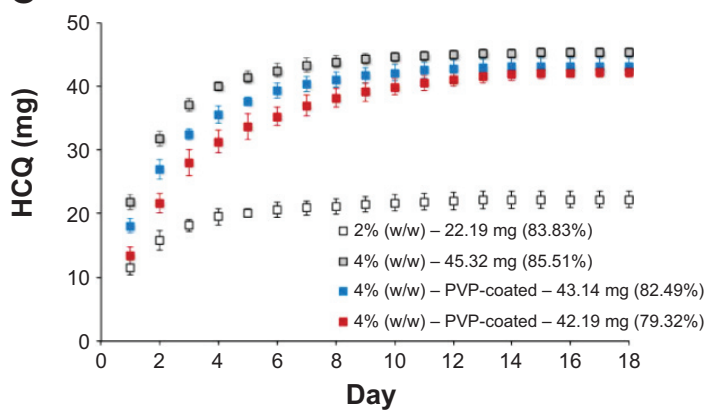

E

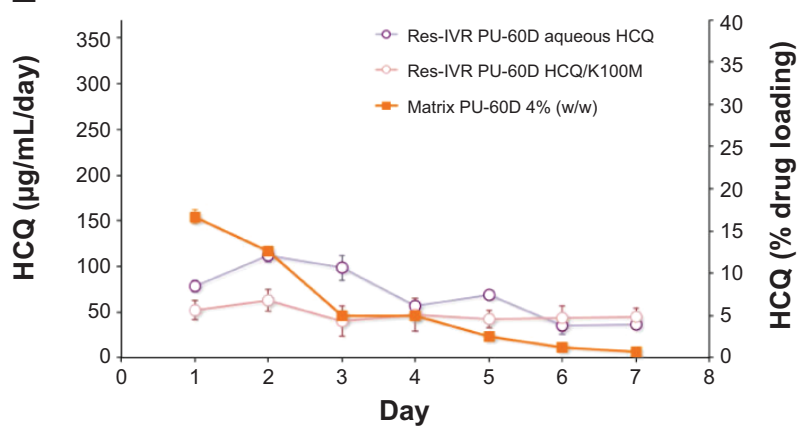

B

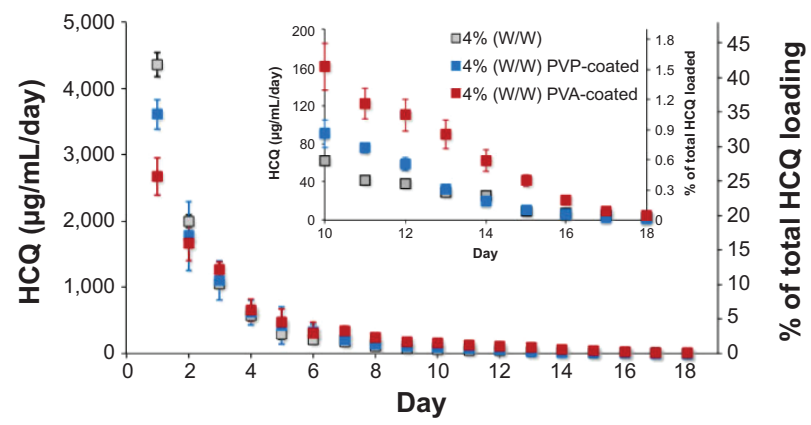

D

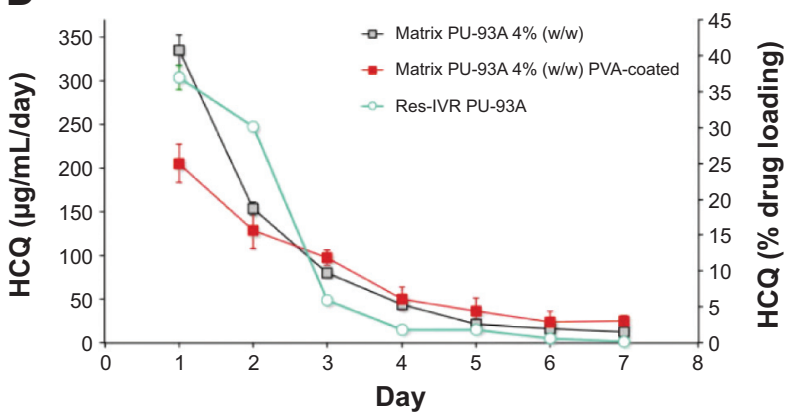

F

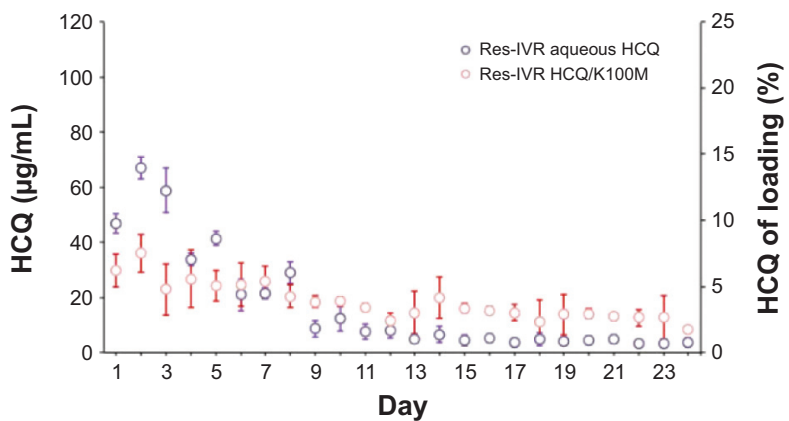

G

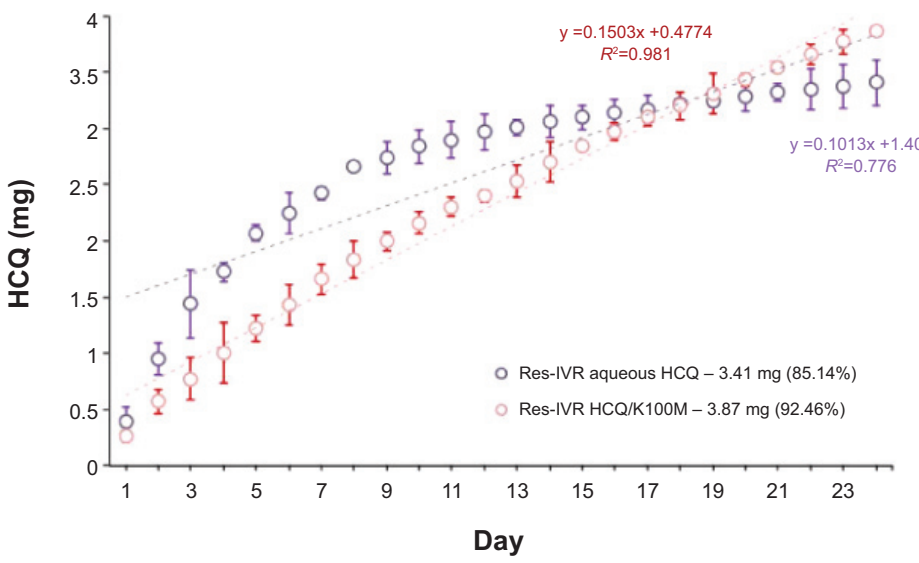

Figure 2 In vitro release of hydroxychloroquine (HCQ) from matrix intravaginal rings (IVRs) and res-IVRs.

Notes: (A) HCQ efflux from a 2\% (w/w) noncoated PU-93A IVR and (B) 4\% (w/w) noncoated, polyvinylpyrrolidone/poly(vinyl alcohol)-coated PU-93A IVRs. Data were scaled up to represent the release from a full-size small IVR. Inset graphs show daily release rates of different HCQ loadings from day 10 to day I8. (C) Cumulative release of HCQ from noncoated and polyvinylpyrrolidone/poly(vinyl alcohol)-coated PU-93A matrix full-size small IVRs. The total cumulative release (percentage) of HCQ from different IVRs is indicated in brackets. (D) Daily release of $4 \mathrm{mg} \mathrm{HCQ}$ total loading from either matrix or res-IVRs fabricated from (D) PU-93A or (E) PU-60D within initial 7 days. (F) Daily release and (G) cumulative release of HCQ from PU-60D res-IVR segments with either aqueous HCQ (purple) or HCQ/KI00M (I:I wt ratio) semisolid (red) containing $4 \mathrm{mg}$ of total HCQ loaded. Linear cumulative HCQ release was calculated for both res-IVRs. Data is expressed as mean \pm SD; $n=6$ for $2 \%$ and $4 \%$ (w/w) matrix IVRs, $n=4$ for polyvinylpyrrolidone/poly(vinyl alcohol)-coated $4 \%(w / w)$ matrix IVRs and $n=3$ for all the other IVRs.

Abbreviations: res-IVRs, reservoir intravaginal rings; PVP, polyvinylpyrrolidone; PVA, poly(vinyl alcohol). 
A

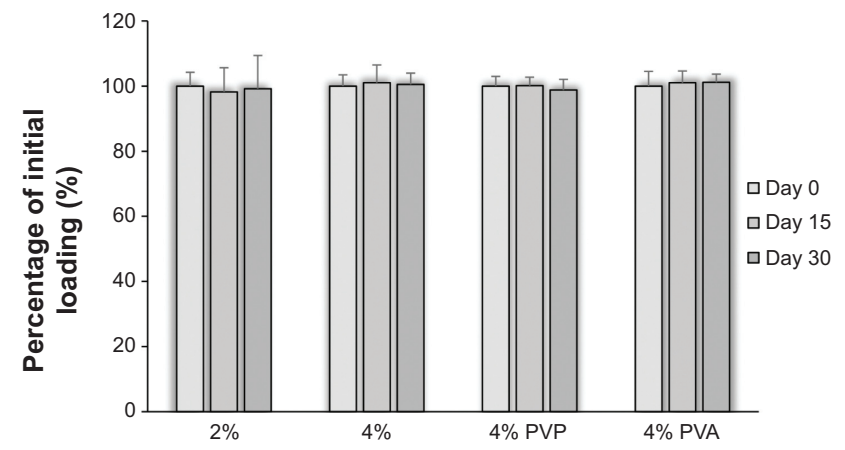

B

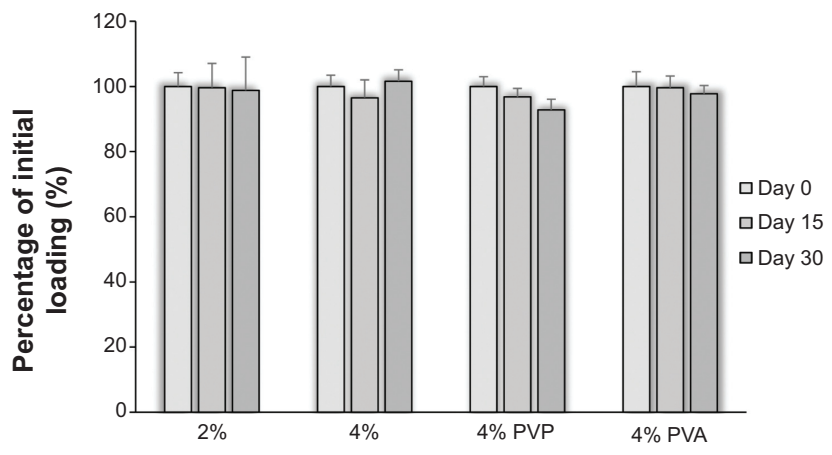

Figure 3 PU-93A matrix intravaginal ring accelerated stability test.

Notes: Hydroxychloroquine extracted from $2 \%(\mathrm{w} / \mathrm{w}), 4 \%(\mathrm{w} / \mathrm{w})$, and polyvinylpyrrolidone, poly(vinyl alcohol)-coated matrix PU-93A intravaginal ring segments incubated for 30 days at (A) room temperature and (B) $40^{\circ} \mathrm{C} / 75 \%$ relative humidity. Data expressed as mean $\pm S D, n=3$.

the latency in reaching the equilibrated state was observed in both types of coated segments (Figure 4), suggesting that swelling may be affected by the PVP or PVA coatings. The reduced swelling resulted in a reduced increase in the weights of the coated segments $(36.90 \%$ and $26.67 \%$ increase on the first day for PVP- and PVA-coated segments, respectively) in comparison with noncoated segments $(47.85 \%$ weight increase).

\section{In vitro cytotoxicity evaluation}

The in vitro biocompatibility of the matrix IVRs developed was evaluated (Figure 5). Elution medium collected after 30 days from noncoated drug-free hot injection molded IVR segments as well as the PVP/PVA-coated segments appeared to have no significant effect on the viability of the vaginal epithelial cell line VK2/E6E7 or the ectocervical

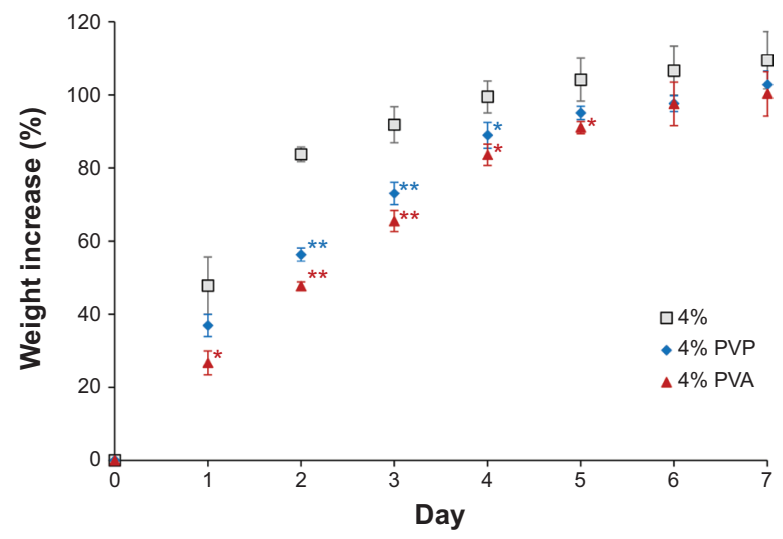

Figure 4 Swelling test of PU-93A matrix intravaginal ring segments.

Notes: Noncoated and coated $4 \%(\mathrm{w} / \mathrm{w})$ hydroxychloroquine PU-93A intravaginal ring segments were incubated in sodium acetate buffer $(\mathrm{pH} 4)$ for 7 days at $37^{\circ} \mathrm{C}$. Noncoated segments reached equilibrated state (no significant mass change) after 2 days, whereas PVP- or PVA-coated segments reached equilibrated state after 5 days of incubation. Data expressed as mean $\pm S D, n=3$. $* P<0.05$ and $* * P<0.001$ versus noncoated matrix segments.

Abbreviations: PVP, polyvinylpyrrolidone; PVA, poly(vinyl alcohol). epithelial cell line Ect1/E6E7 when compared with the negative control (Figure 5A). In contrast, treatment of cells with $1 \mathrm{M}$ acrylamide (positive control) significantly reduced cell viability by $90 \%$. Furthermore, no significant differences were observed in the production of the proinflammatory cytokines IL-1 $\beta$ (Figure 5B), IL-6 (Figure 5C), and IL-8 (Figure 5D) in comparison with the negative control. Results from the colony formation assay using VK2/E6E7 and Ect1/ E6E7 cells are shown in Figure 5E. No significant inhibition of cell colony formation was observed in both cell lines treated with elution medium from either noncoated or PVP/ PVA-coated segment.

\section{Discussion}

The vaginal route has been used for the administration of a wide range of therapeutic agents for women, such as those for contraception and those for the treatment of local vaginal infections. Compared with oral route of administration, vaginal delivery avoids gastric irritation, ${ }^{35}$ bypasses hepatic first-pass metabolism, and can achieve relatively higher drug concentrations in vaginal mucosal tissues while reducing systemic uptake. ${ }^{36,37}$ Drug absorption across the vaginal epithelium membrane involves three sequential steps: release of the drug from the delivery system, dissolution of the drug into vaginal fluid within the vaginal lumen, and membrane penetration of the drug. ${ }^{38}$ Various dosage forms for intravaginal drug delivery have been developed. Among these delivery strategies, the IVR dosing regimen can provide sustained drug delivery, allowing therapeutic effects to be obtained using lower daily doses, which provides effective local drug concentrations at the vaginal mucosa without causing systemic toxicity. ${ }^{39,40}$ Furthermore, studies have indicated that the presence of immunologically quiescent $\mathrm{T}$-cells in the FGT may be correlated with resistance to HIV infection. ${ }^{41-43}$ 
A

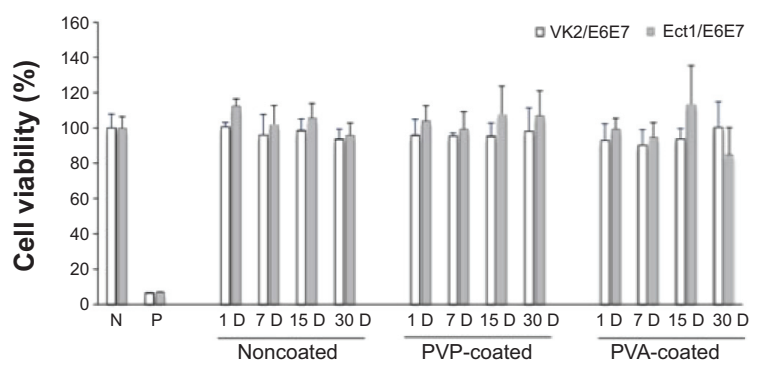

C

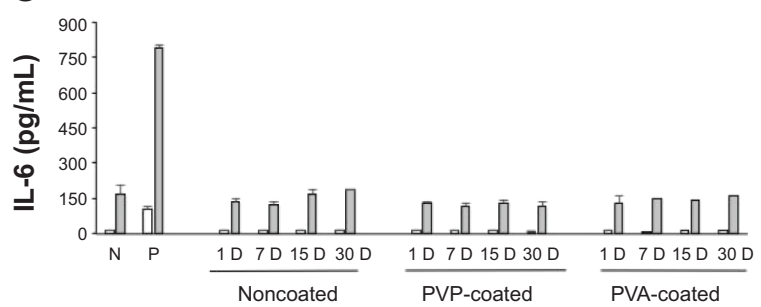

B

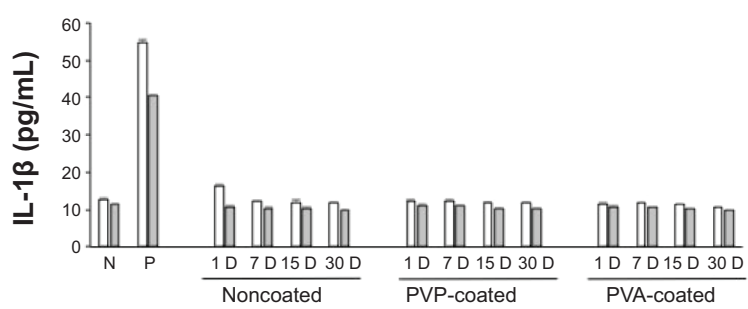

D

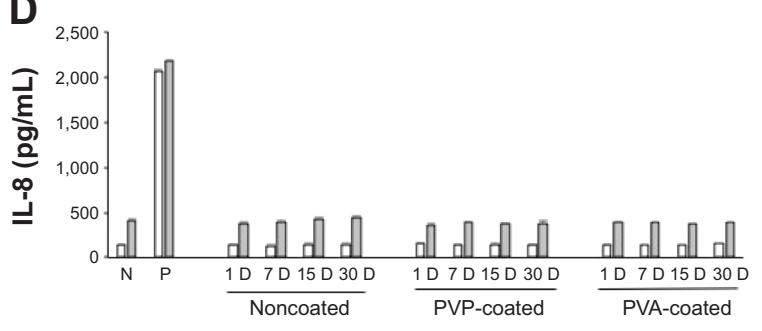

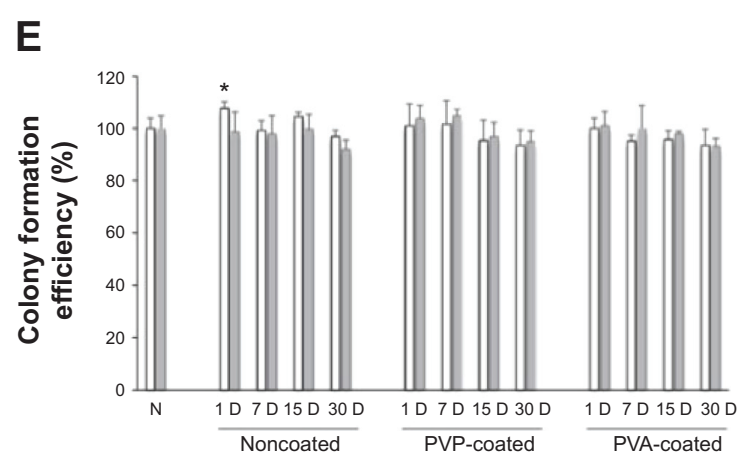

Figure 5 In vitro biocompatibility evaluations of hot-melt intravaginal ring segments.

Notes: (A) MTS assay was performed to determine cell viability. Cells cultured in drug-free medium were used as negative control; I M acrylamide prepared in culture medium was used to induce cell death as a positive control. (B) Interleukin (IL) I $\beta$, (C) interleukin 6, and (D) interleukin 8 production were determined by enzyme-linked immunosorbent assay. Drug-free medium was used as a negative control, and $200 \mu \mathrm{g} / \mathrm{mL}$ of nonoxynol-9 or $50 \mu \mathrm{g} / \mathrm{mL}$ of lipopolysaccharide-treated cells were used as positive controls for interleukin I $\beta$ and interleukin 6/interleukin 8, respectively. (E) Colony formation assay was performed to determine the cell proliferation potential after cell incubation with elution medium for 12 days. Cells cultured in drug-free medium were used as a negative control. Data were normalized to the negative control and expressed as mean $\pm S D, n=3$ except $A(n=5)$. $* P<0.05$ versus negative control.

Abbreviations: N, negative control; P, positive control; PVP, polyvinylpyrrolidone; PVA, poly(vinyl alcohol).

As a result, developing an IVR that can provide sustained controlled HCQ release may potentially protect against HIV infection by reducing the amount of activated T-cells (targets for HIV infection) or directly interacting with components important to viral infection/replication.

Studies have demonstrated that the inhibition of T-cell activation by HCQ is through the inhibition of T-cell-receptorinduced up-regulation of the T-cell activation marker CD69. ${ }^{28}$ Early T-cell activation was suppressed by HCQ at concentrations as low as $4.34 \mu \mathrm{g} / \mathrm{mL}(10 \mu \mathrm{M})$, with effects being dose-dependent. ${ }^{28}$ Expression of CD69 was reduced by $80 \%$ in cells treated with $43.4 \mu \mathrm{g} / \mathrm{mL}(100 \mu \mathrm{M})$ of HCQ without any toxic effect on cell viability or any effects on the level of T-cell surface expression of TCR/CD3, CD4, and CD45 (an essential regulator of T- and B-cell antigen receptor-mediated activation). Furthermore, HCQ has been shown to elicit direct anti-HIV effects via the inhibition of HIV replication in primary T-cells and monocytes..$^{21,22}$ It was reported by Tsai and colleagues that approximately $6.48 \mu \mathrm{g} / \mathrm{mL}(15 \mu \mathrm{M})$ of HCQ was required to produce $50 \%$ viral inhibition. ${ }^{44}$ By measuring the reverse transcriptase activity, Sperber and colleagues reported $75 \%$ of HIV replication could be inhibited in HIV-1 $1_{\text {III-B }}$ challenged primary T-cells or monocytes when the cells were pretreated with $433.96 \mu \mathrm{g} / \mathrm{mL}$ ( $1 \mathrm{mM}$ ) HCQ for 1 hour. ${ }^{22}$ A prolonged in vitro inhibition of HIV replication was maintained within 14 days after this pretreatment because HIV-1 produced from HCQtreated T-cells and monocytic cells poorly infected other cells. ${ }^{22}$ Taking into consideration that vaginal fluid secretion varies between 2 and $8 \mathrm{~mL}$ per day in the normal $\mathrm{FGT}^{45}$ and 
that, in general, PU-based IVR systems demonstrate lower release rates in vivo than the rates observed in vitro, ${ }^{46,47}$ effective HCQ concentrations for maintaining T-cell quiescence within the FGT and for inhibiting HIV replication could be achieved for longer periods ( $>30$ days), using our surface-modified matrix IVR devices. Although Sperber and colleagues reported that cell viability was not affected when T-cell or monocytic cell lines were treated with $0.04 \mu \mathrm{g} / \mathrm{mL}$ $(0.1 \mu \mathrm{M})$ to $433.96 \mu \mathrm{g} / \mathrm{mL}(1 \mathrm{mM})$ of HCQ in vitro, ${ }^{21,22}$ there may still be potential cytotoxicity concerns because of the initial high burst release rates of HCQ from the matrix IVR systems. As a result, we developed a res-IVR with a reduced HCQ loading, which eliminated the burst release on the first day and can provide lower, near-zero-order HCQ release $\left(R^{2}=0.981\right)$, with an average daily release rate of $32.23 \mu \mathrm{g} / \mathrm{mL}$ per day for 24 days (Figure $2 \mathrm{~F}$ and $\mathrm{G}$ ).

As mentioned earlier, release rates in vivo may be lower than those observed in vitro because of vaginal "wash-out" of drug and the variance in vaginal fluid volume production. With this taken into consideration, our res-IVR design allows us to easily increase the rate of HCQ release by increasing the HCQ loading in each res-IVR segment or by including multiple res-IVR segments (up to three segments) into a single IVR (Figure 1B and D). Hence, a sufficient amount of HCQ could be released to achieve the target concentration to induce local T-cell immune quiescence and inhibition of HIV replication within the FGT. In addition, intravaginal delivery of HCQ for the prevention of HIV infection may potentially reduce the development of multidrug resistance because of its combination of effects on both host cells and virus. For example, HCQ has modulatory effects on host immunity ${ }^{29}$ and can directly affect HIV replication via the impairment of posttranslational activities such as glycosylation of gp $120 .{ }^{21}$ Furthermore, because our IVRs are designed to act locally within the FGT, this will minimize any potential systemic adverse effects that may be observed if HCQ were administered orally. Indeed, in vivo studies using the current HCQ-loaded IVR design will be evaluated in the future to determine its effects on immune quiescence induction and HIV replication inhibition in the FGT.

In a typical matrix-based IVR, the drug is uniformly dispersed within the elastomeric polymer matrix. Drug is eluted from the matrix in the radial direction via passive diffusion mechanism. ${ }^{48}$ It is likely that the drug release pattern of a matrix IVR is mainly affected by the following parameters: the amount of drug loaded into the polymeric matrix, which is determined by the "solubility" of drug in the chosen elastomeric polymer and, in turn, affects the total amount of drug that can be released from the matrix; the chemical nature of the drug, such as its water solubility and hydrophobicity; ${ }^{32}$ the physicochemical properties of the polymer matrix, such as hydrophobicity and swelling ability; ${ }^{49}$ and the exposed surface area of the IVR device. ${ }^{50}$ In the current study, a hydrophilic PU-93A was chosen for fabricating the matrix IVR because of the higher cumulative drug release that could be achieved using PU-93A in comparison with other polymeric matrices such as silicone or ethylene vinyl acetate. ${ }^{10}$ More than $80 \%$ of total HCQ loaded was observed to be released from both $2 \%$ and $4 \%(\mathrm{w} / \mathrm{w})$ formulations, whereas segments coated with PVP or PVA demonstrated reduced total release of HCQ (Figure 2B). During the drug elution process from a matrix IVR device, the drug will undergo simple diffusion out of the device into the vaginal fluid. As the drug depletion zone increases, the surface area of the drug core exposed to the fluid decreases, resulting in a declining drug release profile. ${ }^{51}$ This may explain the decreasing daily release rate of the current matrix IVR. The burst release effect is commonly observed in matrix-based IVRs. ${ }^{34,47,50}$ The extent of burst release appears to be related to the water solubility of the drug. It was observed that during the first 24 hours, HCQ release from the same hydrophilic PU-93A matrix with the same drug loading $(2 \%, w / w)$ was nearly twofold and fourfold higher in comparison with the release of two other relatively low-water-soluble drugs, saquinavir and atazanavir, respectively (data not shown). Furthermore, the hydrophilic nature and high swelling properties of the PU-93A could be another reason contributing to the burst effect. Because it takes less time to hydrate the polymeric matrix compared with hydrophobic PUs, the polymeric matrix can swell, allowing a sudden increase in drug diffusion. PUs with higher water swellability demonstrated higher drug release rates. ${ }^{49}$

In the current study, the decreased swelling may be correlated with a decreased burst release, as observed in the coated segments on the first day. We believe less water was able to penetrate the PU-93A, allowing for a slower hydration of the drug core and resulting in reduced drug release. In the present study, PVP- and PVA-coated segments demonstrated a $6.45 \%$ and $15.72 \%$ drop in the burst release rate, respectively (Figure 2B). Although PVP and PVA have been applied in many controlled drug release formulations, ${ }^{52-55}$ their effect on PU-93A swelling is unknown. Although further investigation is necessary to understand the mechanism of this action, the observed delayed swelling of PU-93A in the coated IVR segments could be attributed to the decelerated water penetration into the PU-93A matrix as a result of the presence of hydrophilic PVP and PVA coating. 
Another strategy for overcoming the burst release would be to alter the design of IVR from matrix to reservoirbased. Reservoir-type IVRs have been investigated for the controlled release of various compounds in preclinical microbicide development. ${ }^{46,56}$ In the current study, a hot-melt injection molded res-IVR design was introduced to achieve a near zero-order HCQ release profile (Figure 2F and G). Studies were performed using res-IVR segments, rather than a full-size res-IVR to save on the cost of drugs and polymers. Theoretically, the use of IVR segments should not demonstrate any significant difference in release rates, polymeric swelling, or drug diffusion mechanism. ${ }^{32}$ The reason is because the IVR segments used in this study have been "end-capped" to mimic a complete full-size IVR that does not have any exposed ends. Because the IVR segments have the same cross-sectional diameter and are fabricated from the same polymers as a full-size IVR, the release profile for HCQ from a full-size IVR can be easily extrapolated.

PUs with varying water swellability were investigated for their effects on HCQ release. Reservoir-based IVRs have been shown to demonstrate a first-day burst effect, followed by a constant release profile. ${ }^{48}$ From the results, it was observed that the higher the degree of PU swelling, the greater uncontrollable efflux of HCQ (Figure 2D and E). Fabricating res-IVR segments from PU-60D reduced the burst release compared with res-IVR segments made from PU-93A. Furthermore, it was the first time, to our knowledge, to show that preformulating HCQ into a semisolid mixed with the rate-controlling agent, a high-viscosity HPMC, burst release could be eliminated (Figure $2 \mathrm{~F}$ and $\mathrm{G}$ ).

In addition to providing sustained drug release, an ideal IVR formulation should demonstrate a high degree of stability during storage and excellent biocompatibility. In regions that are affected greatly by HIV (eg, Sub-Saharan Africa, India, and Thailand), the ambient temperature is relatively high $\left(30^{\circ} \mathrm{C}-40^{\circ} \mathrm{C}\right)$, and people living in these developing countries sometimes do not have access to refrigerators. In the current study, when exposing our HCQ-loaded IVRs to accelerated stressed conditions $\left(40^{\circ} \mathrm{C} / 75 \%\right.$ relative humidity), there was no significant loss of HCQ in any of the evaluated matrix IVR formulations when compared with controls (Figure 3). These results are consistent with the forced degradation studies performed by Saini and Bansal, whereby it was demonstrated that HCQ was only unstable under photolytic alkaline conditions. ${ }^{57}$ Furthermore, it was reported by Ferriter et al that PUs were more stable in acidic $\mathrm{pH}$ environments than alkaline. ${ }^{58}$ The daily $\mathrm{pH}$ measurement of the collected release medium remained unchanged at a $\mathrm{pH}$ of 4 during the entire HCQ release study period. This indicates that HCQ released from the IVRs had no significant effect on the $\mathrm{pH}$ of the release buffer. Furthermore, the PU used for IVR development should also exhibit good stability without any compromise to the mechanical properties of the IVR while being exposed to an acidic humidified environment. Previous studies have shown that IVRs fabricated from PU-60D did not demonstrate any changes in mechanical property (elastic modulus) or drug release profile in vitro or in vivo after being exposed to acidic conditions during a 90 days study period. ${ }^{56}$ These findings indicate that the degradation of PU-60D in aqueous or highly humidified acidic environments are negligible, with little effect on both the stability of the IVR device and the drug-release profile.

Previously failed microbicide trials using cellulose sulfate and nonoxynol-9 were a result of the disruption of tight junctions and the induction of inflammation in the FGT, characterized by elevated IL-1 and IL-8 expression. ${ }^{59,60}$ Thus, the development of any intravaginal microbicide needs to be evaluated for its effect on epithelial cell viability and its potential to induce pro-inflammatory cytokine production. In the current study, there was no significant induction of pro-inflammatory cytokines or reduction in cell viability, further supporting the fact that our IVR delivery system is noncytotoxic (Figure 5A and B). Using the vaginal and ectocervical epithelial cells, drug-free IVR segments had no significant effect on the viability of epithelial cells even up to 30 days of incubation. By employing the colony formation assay, often used as a sensitive approach for cytotoxic examination of individually treated cells, ${ }^{61,62}$ it was demonstrated that no significant inhibition in colony formation was observed, suggesting that the hydrophilic polyurethane, as well as PVP/PVA coating, has no influence on cell division after prolonged exposure (Figure 5C). The healthy human vagina is dominated by lactobacilli, playing an important role in protecting the host from urogenital infections. Lactobacilli are gram-positive, protective organisms found in the normal FGT that play an important role in maintaining a healthy acidic environment by producing lactic acid to inhibit the growth of pathogenic organisms. To date, there are no studies performed investigating the direct administration of HCQ within the FGT and its effect specifically on the Lactobacillus strains predominantly present in a healthy FGT. In fertile women, the most frequently identified strains of Lactobacillus within the FGT are Lactobacillus crispatus and Lactobacillus acidophilus. ${ }^{63}$ Although Angelakis and colleagues recently reported that long-term HCQ treatment could affect the prevalence of total Lactobacillus species residing within 
the gastrointestinal tract, ${ }^{64}$ no direct evidence has been shown that HCQ may affect the prevalence of either L. crispatus or L. acidophilus strains, as they were found to be sporadically present in the gastrointestinal microbiota. ${ }^{65}$ Since the HCQ release can be controlled via our IVR systems by the alteration of either the design (matrix and reservoir segmental IVRs) or drug loading, we believe we can achieve an HCQ dose that will have minimal effect on the microbiota within the FGT while maintaining therapeutic efficacy against HIV. Nevertheless, future studies are in need to determine the effect of intravaginal delivery of HCQ on the microbial flora in the FGT and its role in HIV infection.

\section{Conclusion}

This is the first study to our knowledge to fabricate a matrix-type IVR and a res-IVR that can provide sustained in vitro release of HCQ for more than 14 days. This is also the first study to demonstrate that IVRs coated with PVA or PVP can significantly reduce the burst release of HCQ within the first 24 hours. Fabrication of res-IVRs from lowwater-swellable PUs demonstrated a near-zero-order release profile when HCQ was preformulated into a semisolid dosage form. HCQ in the IVR was stable under accelerated stressed conditions, and the IVR was noncytotoxic when incubated in the presence of human vaginal and ectocervical epithelial cell lines. Overall, the current study indicates that the developed IVR devices can potentially be used for the intravaginal delivery of HCQ. Further in vivo studies are required to determine the effect of our HCQ IVR on the induction of immune quiescence within the FGT for preventing HIV infection.

\section{Acknowledgments}

We thank Dr Neal M Davies for access to his HPLC equipment. We also thank Ms Dan Zhang from the Department of Clinical Pharmacology, Aerospace Center Hospital, in the People's Republic of China, and Ms Sidi Yang for their assistance with the RP-HPLC analysis of HCQ and drug extraction. This work was supported in part by a Canadian Institutes of Health Research Operating Grant (MOP110981) awarded to E.A.H., a grant from the Bill and Melinda Gates Foundation (OPP1007233GCE) awarded to E.A.H., and a Canadian Institutes of Health Research Canadian HIV Vaccine Initiative Grant (OCH-126275) awarded to K.R.F. Y.C. was supported by a graduate studentship from the Manitoba Health Research Council. The funders had no role in study design, data collection and analysis, decision to publish, or preparation of the manuscript.

\section{Disclosure}

The authors report no conflicts of interest in this work.

\section{References}

1. United Nations Programme on HIV/AIDS. Data Table 2011. Geneva: United Nations Programme on HIV/AIDS; 2011. Available from: http://www.unaids.org/en/media/unaids/contentassets/documents/ unaidspublication/2011/JC2225_UNAIDS_datatables_en.pdf. Accessed July 3, 2013.

2. United Nations Programme on HIV/AIDS. UNAIDS Report on the Global AIDS Epidemic: 2010. Geneva: United Nations Programme on HIV/AIDS; 2010. Available from: http://www.unaids.org/ documents/20101123_GlobalReport_em.pdf. Accessed May 23, 2013.

3. United Nations Programme on HIV/AIDS. UNAIDS World AIDS Day Report 2011. Geneva: United Nations Programme on HIV/AIDS; 2011. Available from: http://www.unaids.org/en/media/unaids/contentassets/ documents/unaidspublication/2011/jc2216_worldaidsday_report_2011_ en.pdf. Accessed June 20, 2013.

4. Abdool Karim Q, Abdool Karim SS, Frohlich JA, et al; CAPRISA 004 Trial Group. Effectiveness and safety of tenofovir gel, an antiretroviral microbicide, for the prevention of HIV infection in women. Science. 2010;329(5996):1168-1174.

5. Gengiah TN, Baxter C, Mansoor LE, Kharsany AB, Abdool Karim SS A drug evaluation of $1 \%$ tenofovir gel and tenofovir disoproxil fumarate tablets for the prevention of HIV infection. Expert Opin Investig Drugs. 2012;21(5):695-715.

6. van der Straten A, Van Damme L, Haberer JE, Bangsberg DR. Unraveling the divergent results of pre-exposure prophylaxis trials for HIV prevention. AIDS. 2012;26(7):F13-F19.

7. Kiser PF, Mahalingam A, Fabian J, et al. Design of tenofovir-UC781 combination microbicide vaginal gels. J Pharm Sci. 2012;101(5): 1852-1864.

8. National Institute of Allergy and Infectious Diseases. Safety and effectiveness of tenofovir $1 \%$ gel, Tenofovir disproxil fumarate, and emtricitabine/tenofovir disoproxil fumarate tablets in preventing HIV in women. Available from: http://clinicaltrials.gov/ct2/show/ NCT00705679. NLM identifier: NCT00705679. Accessed: May 29, 2013.

9. Montgomery ET, van der Straten A, Cheng H, et al. Vaginal ring adherence in sub-Saharan Africa: expulsion, removal, and perfect use. AIDS Behav. 2012;16(7):1787-1798.

10. Mesquita PM, Rastogi R, Segarra TJ, et al. Intravaginal ring delivery of tenofovir disoproxil fumarate for prevention of HIV and herpes simplex virus infection. J Antimicrob Chemother. 2012;67(7):1730-1738.

11. Moss JA, Malone AM, Smith TJ, et al. Simultaneous delivery of tenofovir and acyclovir via an intravaginal ring. Antimicrob Agents Chemother. 2012;56(2):875-882.

12. Moss JA, Malone AM, Smith TJ, et al. Safety and pharmacokinetics of intravaginal rings delivering tenofovir in pig-tailed macaques. Antimicrob Agents Chemother. 2012;56(11):5952-5960.

13. Malcolm RK, Woolfson AD, Toner CF, Morrow RJ, McCullagh SD. Long-term, controlled release of the HIV microbicide TMC120 from silicone elastomer vaginal rings. J Antimicrob Chemother. 2005; 56(5):954-956.

14. Hussain A, Ahsan F. The vagina as a route for systemic drug delivery. J Control Release. 2005;103(2):301-313.

15. Fox R. Anti-malarial drugs: possible mechanisms of action in autoimmune disease and prospects for drug development. Lupus. 1996; 5(1 suppl)(suppl 1):S4-S10.

16. Chung HS, Hann SK. Lupus panniculitis treated by a combination therapy of hydroxychloroquine and quinacrine. J Dermatol. 1997;24(9): 569-572.

17. Ben-Zvi I, Kivity S, Langevitz P, Shoenfeld Y. Hydroxychloroquine: from malaria to autoimmunity. Clin Rev Allergy Immunol. 2012;42(2): $145-153$. 
18. Hackstadt T, Williams JC. Biochemical stratagem for obligate parasitism of eukaryotic cells by Coxiella burnetii. Proc Natl Acad Sci US A. 1981;78(5):3240-3244.

19. Raoult D, Houpikian P, Tissot Dupont H, Riss JM, Arditi-Djiane J, Brouqui P. Treatment of Q fever endocarditis: comparison of 2 regimens containing doxycycline and ofloxacin or hydroxychloroquine. Arch Intern Med. 1999;159(2):167-173.

20. Fenollar F, Fournier PE, Carrieri MP, Habib G, Messana T, Raoult D. Risks factors and prevention of Q fever endocarditis. Clin Infect Dis. 2001;33(3):312-316.

21. Chiang G, Sassaroli M, Louie M, Chen H, Stecher VJ, Sperber K. Inhibition of HIV-1 replication by hydroxychloroquine: mechanism of action and comparison with zidovudine. Clin Ther. 1996;18(6):1080-1092.

22. Sperber K, Kalb TH, Stecher VJ, Banerjee R, Mayer L. Inhibition of human immunodeficiency virus type 1 replication by hydroxychloroquine in T-cells and monocytes. AIDS Res Hum Retroviruses. 1993;9(1):91-98.

23. Naarding MA, Baan E, Pollakis G, Paxton WA. Effect of chloroquine on reducing HIV-1 replication in vitro and the DC-SIGN mediated transfer of virus to CD4+ T-lymphocytes. Retrovirology. 2007;4(1):6.

24. Rayne F, Vendeville A, Bonhoure A, Beaumelle B. The ability of chloroquine to prevent tat-induced cytokine secretion by monocytes is implicated in its in vivo anti-human immunodeficiency virus type 1 activity. J Virol. 2004;78(21):12054-12057.

25. Sperber K, Louie M, Kraus T, et al. Hydroxychloroquine treatment of patients with human immunodeficiency virus type 1. Clin Ther. 1995; 17(4):622-636.

26. Paton NI, Aboulhab J, Karim F. Hydroxychloroquine, hydroxycarbamide, and didanosine as economic treatment for HIV-1. Lancet. 2002; 359(9318):1667-1668.

27. Gilman AL, Chan KW, Mogul A, et al. Hydroxychloroquine for the treatment of chronic graft-versus-host disease. Biol Blood Marrow Transplant. 2006(3A):327-334.

28. Goldman FD, Gilman AL, Hollenback C, Kato RM, Premack BA, Rawlings DJ. Hydroxychloroquine inhibits calcium signals in T-cells: a new mechanism to explain its immunomodulatory properties. Blood. 2000;95(11):3460-3466.

29. Piconi S, Parisotto S, Rizzardini G, et al. Hydroxychloroquine drastically reduces immune activation in HIV-infected, antiretroviral therapy-treated immunologic nonresponders. Blood. 2011;118(12):3263-3272.

30. Shattock RJ, Moore JP. Inhibiting sexual transmission of HIV-1 infection. Nat Rev Microbiol. 2003;1(1):25-34.

31. Promadej-Lanier N, Smith JM, Srinivasan P, et al. Development and evaluation of a vaginal ring device for sustained delivery of HIV microbicides to non-human primates. J Med Primatol. 2009;38(4):263-271.

32. Johnson TJ, Gupta KM, Fabian J, Albright TH, Kiser PF. Segmented polyurethane intravaginal rings for the sustained combined delivery of antiretroviral agents dapivirine and tenofovir. Eur J Pharm Sci. 2010; 39(4):203-212.

33. Volin P. Simple and specific reversed-phase liquid chromatographic method with diode-array detection for simultaneous determination of serum hydroxychloroquine, chloroquine and some corticosteroids. J Chromatogr B Biomed Appl. 1995;666(2):347-353.

34. Kiser PF, Johnson TJ, Clark JT. State of the art in intravaginal ring technology for topical prophylaxis of HIV infection. AIDS Rev. 2012;14(1): 62-77.

35. Vermesh M, Fossum GT, Kletzky OA. Vaginal bromocriptine: pharmacology and effect on serum prolactin in normal women. Obstet Gynecol. 1988;72(5):693-698.

36. Patel LG, Warrington SJ, Pearson RM. Propranolol concentrations in plasma after insertion into the vagina. Br Med J (Clin Res Ed). 1983; 287(6401):1247-1248.

37. D'Cruz OJ, Uckun FM. Vaginal microbicides and their delivery platforms. Expert Opin Drug Deliv. 2014;11(5):723-740.

38. Woolfson ADRM, Rathbone MJ, Hadgraft J. Intravaginal Drug Delivery Technologies. New York: Marcel Dekker; 2008:754-774.

39. Srikrishna S, Cardozo L. The vagina as a route for drug delivery: a review. Int Urogynecol J. 2013;24(4):537-543.
40. Ho EA. Intravaginal Rings as a Novel Platform for Mucosal Vaccination. J Mol Pharm Org Process Res. 2013;1(2):e103.

41. Lajoie J, Juno J, Burgener A, et al. A distinct cytokine and chemokine profile at the genital mucosa is associated with HIV-1 protection among HIV-exposed seronegative commercial sex workers. Mucosal Immunol. 2012;5(3):277-287.

42. Iqbal SM, Ball TB, Kimani J, et al. Elevated T-cell counts and RANTES expression in the genital mucosa of HIV-1-resistant Kenyan commercial sex workers. J Infect Dis. 2005;192(5):728-738.

43. Songok EM, Luo M, Liang B, et al. Microarray analysis of HIV resistant female sex workers reveal a gene expression signature pattern reminiscent of a lowered immune activation state. PLOS ONE. 2012; 7(1):e30048.

44. Tsai WP, Nara PL, Kung HF, Oroszlan S. Inhibition of human immunodeficiency virus infectivity by chloroquine. AIDS Res Hum Retroviruses. 1990;6(4):481-489.

45. Saltzman W. Drug Delivery: Engineering Principles for Drug Therapy. New York: Oxford University Press; 2001.

46. Clark JT, Clark MR, Shelke NB, et al. Engineering a segmented dual-reservoir polyurethane intravaginal ring for simultaneous prevention of HIV transmission and unwanted pregnancy. PLOS ONE. 2014;9(3):e88509.

47. Clark MR, Johnson TJ, McCabe RT, et al. A hot-melt extruded intravaginal ring for the sustained delivery of the antiretroviral microbicide UC781. J Pharm Sci. 2012;101(2):576-587.

48. Malcolm RK, Edwards KL, Kiser P, Romano J, Smith TJ. Advances in microbicide vaginal rings. Antiviral Res. 2010;88(suppl 1):S30-S39.

49. Johnson TJ, Clark MR, Albright TH, et al. A 90-day tenofovir reservoir intravaginal ring for mucosal HIV prophylaxis. Antimicrob Agents Chemother. 2012;56(12):6272-6283.

50. Clark JT, Johnson TJ, Clark MR, et al. Quantitative evaluation of a hydrophilic matrix intravaginal ring for the sustained delivery of tenofovir. J Control Release. 2012;163(2):240-248.

51. Malcolm RK, Fetherston SM, McCoy CF, Boyd P, Major I. Vaginal rings for delivery of HIV microbicides. Int J Womens Health. 2014: 595-605.

52. Fan C, Pai-Thakur R, Phuapradit W, et al. Impact of polymers on dissolution performance of an amorphous gelleable drug from surface-coated beads. Eur J Pharm Sci. 2009;37(1):1-10.

53. Ensslin S, Moll KP, Paulus K, Mäder K. New insight into modified release pellets - Internal structure and drug release mechanism. $J$ Control Release. 2008;128(2):149-156

54. Shen J, Burgess DJ. Accelerated in vitro release testing of implantable PLGA microsphere/PVA hydrogel composite coatings. Int J Pharm. 2012;422(1-2):341-348.

55. Siepmann F, Eckart K, Maschke A, Kolter K, Siepmann J. Modeling drug release from PVAc/PVP matrix tablets. J Control Release. 2010; 141(2):216-222.

56. Johnson TJ, Clark MR, Albright TH, et al. A 90-day tenofovir reservoir intravaginal ring for mucosal HIV prophylaxis. Antimicrob Agents Chemother. 2012;56(12):6272-6283.

57. Balraj Saini GB. Characterization of four new photodegradation products of hydroxychloroquine through LC-PDA, ESI-MSn and LC-MSTOF studies. J Pharm Biomed Anal. 2013.

58. Ferriter JP, Meyers CE Jr, Lorton L. The effect of hydrogen ion concentration on the force-degradation rate of orthodontic polyurethane chain elastics. Am J Orthod Dentofacial Orthop. 1990;98(5):404-410.

59. Mesquita PM, Cheshenko N, Wilson SS, et al. Disruption of tight junctions by cellulose sulfate facilitates HIV infection: model of microbicide safety. J Infect Dis. 2009;200(4):599-608.

60. Fichorova RN, Bajpai M, Chandra N, et al. Interleukin (IL)-1, IL-6, and IL-8 predict mucosal toxicity of vaginal microbicidal contraceptives. Biol Reprod. 2004;71(3):761-769.

61. Franken NA, Rodermond HM, Stap J, Haveman J, van Bree C. Clonogenic assay of cells in vitro. Nat Protoc. 2006;1(5):2315-2319.

62. Li W, Lam MS, Birkeland A, et al. Cell-based assays for profiling activity and safety properties of cancer drugs. J Pharmacol Toxicol Methods. 2006;54(3):313-319. 
63. Gustafsson RJ, Ahrné S, Jeppsson B, et al. The Lactobacillus flora in vagina and rectum of fertile and postmenopausal healthy Swedish women. BMC Womens Health. 2011;11(1):17.

64. Angelakis E, Million M, Kankoe S, et al. Abnormal weight gain and gut microbiota modifications are side effects of long-term doxycycline and hydroxychloroquine treatment. Antimicrob Agents Chemother. 2014; 58(6):3342-3347.
65. Walter J. Ecological role of lactobacilli in the gastrointestinal tract: implications for fundamental and biomedical research. Appl Environ Microbiol. 2008;74(16):4985-4996.

\section{Publish your work in this journal}

Drug Design, Development and Therapy is an international, peerreviewed open-access journal that spans the spectrum of drug design and development through to clinical applications. Clinical outcomes, patient safety, and programs for the development and effective, safe, and sustained use of medicines are a feature of the journal, which has also been accepted for indexing on PubMed Central. The manuscript management system is completely online and includes a very quick and fair peer-review system, which is all easy to use. Visit http://www.dovepress.com/testimonials.php to read real quotes from published authors.

Submit your manuscript here: http://www.dovepress.com/drug-design-development-and-therapy-journal 